\title{
Patterns of community composition in two tropical tree frog assemblages: separating spatial structure and environmental effects in disturbed and undisturbed forests
}

\author{
Raffael Ernst ${ }^{1}$ and Mark-Oliver Rödel ${ }^{2}$
}

Department of Biodiversity Dynamics, TU Berlin, Rothenburgstr. 12, 12165 Berlin, Germany

(Accepted 26 November 2007)

\begin{abstract}
An on-going controversy in community ecology involves the debate about the many factors that affect the assembly and composition of a given species assemblage. Theory suggests that community composition is influenced by environmental gradients or biotic processes. This study examines patterns of community composition in two tropical tree frog assemblages of primary and exploited lowland rain-forest sites in the Guiana Shield area of central Guyana, South America and the Upper Guinean rain-forest block of south-western Côte d'Ivoire, West Africa. We tested community composition and species abundance data of two adult tree frog communities collected on 21 standardized transects during a period of $5 \mathrm{y}$ for evidence of spatial correlation in community composition. We applied simple and partial Mantel tests to separate the effects of environmental variables, spatial distance and spatial autocorrelation on community composition. Whenever environmental effects were accounted for, we found significant positive spatial correlation of community composition. All assemblages appeared to be spatially structured, i.e. sites in close proximity had similar species assemblages. However, spatially structured environmental variation (autocorrelation) did not account for the spatial structure of species incidence. Environmental factors did not prove to be significant predictors of species incidence in any of the assemblages analysed, even if we controlled for spatial effects. Observed correlation patterns of species composition were consistent within respective realms and disturbance regimes. Moreover, general correlation patterns were consistent between geographic regions. These results are in contrast to previously published results from a study on leaf-litter anurans and indicate that group-specific differences must not be neglected when analysing patterns of species composition in anurans as they may drastically alter the outcome of the analysis.
\end{abstract}

Key Words: community composition, disturbance, Guyana, Ivory Coast, northern South America, tree frogs, tropical rain forests, spatial structure, West Africa

\section{INTRODUCTION}

Despite the fact that various general patterns in ecology have successfully been identified at the macro-ecological scale (Gaston \& Blackburn 2000) or at species-specific scales (e.g. habitat requirements, Beadle 1966) general rules of community assembly remain elusive. Even the very existence of any assembly rule has been debated (McIntosh 1995). Relationships between incidences of particular species and systematic (patch quality), temporal (seasonal/annual variation) and patch-specific (patch history) variables may often be idiosyncratic,

\footnotetext{
${ }^{1}$ Corresponding author. Email: ernst@biozentrum.uni-wuerzburg.de ${ }^{2}$ Current address: Museum of Natural History, Humboldt University, Invalidenstr. 43, 10115 Berlin, Germany.
}

rather than the majority of species responding to a few dominant factors in a similar way (Jeffries 2003).

Relationships between community structure and environmental conditions have been described as an adaptive process under constraints that can alter how the functional traits of species match up with the environmental conditions that they encounter. Strong correlations between community composition and environmental factors would indicate that this process is indeed influential (Leibold et al. 2005). In the absence of such a process, community composition would not correspond with environmental conditions. The distribution and abundance of species, and thus the composition of entire communities are influenced by environmental parameters (Gleason 1917, 1926; Neave et al. 1996, Parris 2004, Whittaker 1956) 
or biotic processes, such as competition, predation or dispersal (Clements 1916, Connell 1983, McCarthy 1997, McCarthy \& Lindenmayer 2000).

In the first case, particular communities simply reflect the fortuitous correspondence of independent life histories in one place and time. However, even if species-habitat relationships are strong, it would be wrong to assume that environmental variables automatically determine the composition of a given assemblage, because strong stochastic elements to recruitment in the component species and environmental fluctuations can result in variations in community composition (Ernst \& Rödel 2005, 2006).

In the second case communities would be spatially structured i.e. sites in close proximity would have similar species assemblages (Legendre \& Fortin 1989). Spatial habitat heterogeneity may itself be correlated with the spatial distribution of species. This means that systematic, spatially structured, environmental variation can result in a spatial structure of species incidence. Three factors may hence contribute to the variation of community composition. These factors are environmental variation, spatial variation and spatially structured environmental variation (Bocard et al. 1992).

Few studies have investigated the effects of environmental variables and spatial or biotic processes on amphibian community composition (Azavedo-Ramos et al. 1999, Hecnar \& M'Closkey 1997, Hero et al. 1998, Parris 2004, Skelly 1995) and even fewer studies have investigated the effects of anthropogenic disturbance in the same context (Ernst \& Rödel 2005, 2006; Gardner \& Fitzherbert 2007, Gardner et al. 2007).

Among all vertebrate groups, amphibians are the one with the highest proportion of species threatened with extinction (Beebee \& Griffiths 2005, Stuart et al. 2004) and habitat loss and fragmentation have been identified as the most direct contributors to these threats (Bowne \& Bowers 2004, Carr \& Fahrig 2001, Houlahan \& Findlay 2003). There is hence a clear need for studies that focus on the relationship between anthropogenic disturbance and amphibian community structure and composition.

Most of the studies on amphibian community assembly and composition have either focused on entire communities (i.e. no differentiation between different functional groups) or they have concentrated on easily assessable segments of the entire community (e.g. leaf-litter anurans only). To our knowledge, this is the first study to specifically address questions concerning community structure and the impact of anthropogenic disturbance in arboreal anuran communities, a large segment of many amphibian communities (Duellman 1988, 1999).

Approaches that focus on particular groups such as leaf-litter anurans or arboreal anurans might be indispensable if compositional patterns are to be analysed systematically. This is especially true with respect to patterns between community composition and environments as differences in life-history strategies, and thus potential habitat associations, may strongly affect the analysis of correlation patterns. In other words, it may be important which segment of the entire community is being analysed, as patterns may differ between different ecological groups (Ernst et al. 2006, 2007). Because species-environment relationships may differ greatly among different groups across scales (Cushman \& McGarigal 2004) it is even more important to perform analyses on a group-specific basis.

In this study we therefore looked at community processes and patterns of composition in two arboreal amphibian communities in primary and disturbed forest habitats in two geographically distinct eco-regions.

In this context we specifically tested whether: (1) sites with similar environmental characteristics are also similar with respect to species composition (environmental variation) and (2) sites in close proximity are similar with respect to species composition (spatial variation). We also tested for spatial autocorrelation between sampling units (spatially structured environmental variation) and for possible variance of species occurrence due to seasonal changes (temporal signal) and disturbance of the system (disturbance signal). Because there may be large differences among amphibian species in terms of their habitat requirements and sensitivity to environmental changes, which in turn may be closely related to the geographic history of the respective site and the phylogenetic history of the respective species, we decided to take a large-scale comparative approach. We therefore compared arboreal communities of two geographically distinct eco-regions, namely the Neotropical and the Afrotropical realms.

We finally relate our results to the patterns previously found in the terrestrial anuran assemblage of the African forest site (Ernst \& Rödel 2005) and anuran assemblages of forest streams in eastern Australia (Parris 2004).

\section{METHODS}

\section{Study areas and disturbance history}

The Taï National Park (TNP) in south-western Côte d'Ivoire is the largest remaining protected area of rain forest in West Africa. Our study sites $\left(5^{\circ} 50^{\prime} \mathrm{N}\right.$, $7^{\circ} 20^{\prime} \mathrm{W}$ ) comprised about $30 \mathrm{~km}^{2}$ of primary and exploited rain forest. In TNP anthropogenic disturbance (selective logging, coffee and cocoa plantations) ceased approximately $25 \mathrm{y}$ ago. Past human influence was still visible in this area and differences between primary and exploited forest sites were marked (Ernst \& Rödel 2005). For a detailed description of TNP see Riezebos et al. (1994) The Mabura Hill Forest Reserve (MHFR) is situated in Central Guyana $\left(5^{\circ} 13^{\prime} \mathrm{N}, 58^{\circ} 48^{\prime} \mathrm{W}\right)$. It comprises an area of approximately $20 \mathrm{~km}^{2}$ of primary rain forest and is part of the Wappu compartment located within a 500- $\mathrm{km}^{2}$ 
Timber Sales Agreement concession. Disturbed sites were located outside the reserve's core area, within the main logging concession. These sites have been logged with equal intensities (i.e. 19.5 trees or approximately $57 \mathrm{~m}^{3}$ $\left.\mathrm{ha}^{-1}\right)$. For a detailed description of MHFR and disturbance history of particular study sites see Ernst et al. (2005) and ter Steege et al. (1996).

\section{Data acquisition}

The field data were acquired between February 1999 and September 2002 (TNP) and November 2002 and September 2004 (MHFR). We collected wet-season data for a period of 11 mo in TNP; dry-season data cover 4 mo. In MHFR, wet-season data cover 8 mo and dryseason data cover 4 mo. We established 10 transects, six in primary forest, four in exploited forest (TNP) and 11 transects, six in primary forest and five in exploited forest (MHFR), respectively (Ernst et al. 2005, Rödel \& Ernst 2004). In both cases, sites included in the analyses are to be considered as classical chronosequences i.e. assuming equal initial states of sites with different disturbance histories (sensu Plumptre 1996).

Each rectangular transect had a total length of $600 \mathrm{~m}$. Transects were subdivided in 25-m subunits (SUs; 24 SUs per transect). Each SU was characterized using a set of parameters that included vegetation density at four different strata, substrate type, substrate moisture level (substrate parameters reflect water-holding capacity of habitat), percentage of leaf cover, number of woody plants in four different stem diameter at breast height (dbh) categories as a proxy for disturbance status (high number of plants in lower dbh categories = indication of disturbance; high number of plants in higher dbh categories = indication of old-growth forest with important habitat trees), and the availability of potential lentic or lotic aquatic breeding habitats (total of 14 parameters). Only parameters recorded in both eco-regions were considered in the analysis. For species-related calculations we used relative abundance values (individuals per transect hour in each SU). In a comparative analysis of amphibian monitoring programmes using transects in East Africa, West Africa (including the data presented herein), Madagascar and Borneo, we recently have shown that $\geq 20$ independent transect walks seem to be necessary to achieve species saturation (Veith et al. 2004). During this study, each transect was walked independently at least 41 times. It is thus justified to assume that the local communities have been almost completely assessed.

Detailed descriptions and discussion of the transect design, data acquisition routine, tests for independence of sample units (test for spatial autocorrelation of environmental characteristics), and an evaluation of various methods have been published earlier (Ernst \&
Rödel 2005, Rödel \& Ernst 2004). Descriptions given herein are hence restricted to relevant modifications and aspects specific to this study.

\section{Statistical analysis}

We compiled field data into three types of matrix. These were based on (1) species distribution vectors (SDM, species by SU matrix with relative species abundance as cell entry), (2) environmental characteristic vectors (ECM, habitat parameters by SU matrix with respective habitat parameter value as cell entry), and (3) geographic distance vectors (GDM, SU by SU matrix with true geographic distances between SU as cell entry). Based on these original matrices we constructed distance matrices. For SDM we used the Sørensen quantitative (BrayCurtis) index (Faith et al. 1987, Magurran 2004). For ECM we chose the relativized Euclidian distance (RED, Legendre \& Legendre 1998). GDM was not transformed as it represents a distance matrix by definition. The analyses were performed using different sets of matrices corresponding to either primary or exploited forest and to either the entire season or the dry versus the wet season (Ernst \& Rödel 2005).

In order to optimize our model we conducted a preliminary analysis in which we tested for species' response to underlying environmental gradients using a detrended correspondence analysis (DCA) routine following Lepš \& Šmilauer (2004). The procedure tests for unimodal versus linear species' response based on the longest gradient (maximum extent of species turnover along individual independent gradients). Values larger than 4.0 indicate unimodal response, values below 3.0 indicate linear response. If the analysis yields values between 3.0 and 4.0 both types of model describe the response reasonably well. In our case the analysis yielded a value of 3.6, indicating that neither linearity nor unimodality can fully be assumed for all species responses. Hence, linear as well as unimodal models can be applied.

In our particular case we choose Mantel tests because they allow the incorporation of spatial proximity into models of ecological communities and they are sensitive in cases where the species distribution pattern is controlled by a strong directional gradient in addition to a local spatial process (Urban et al. 2002). This is in contrast to widely used constrained ordination techniques such as Canonical Correspondence Analysis (CCA) or Redundancy Analysis (RDA). Incorporating geographic coordinates in these kinds of model would test for a spatial trend in species composition, and would show no relationship if the population was composed of spatially restricted groups of similar individuals over the locality.

We therefore addressed the question of whether there was a correlation between the off-diagonal elements of 
the constructed distance matrices by performing partial Mantel tests. The test evaluates the null hypothesis of no relationship between two dissimilarity (distance) or similarity matrices via partial correlation conditioned on a third matrix. It can thus be considered a firstorder partial correlation analysis conducted on three distance matrices (Smouse et al. 1986). In our analysis we controlled for either ECM or GDM, while permuting SDM. This allows distinguishing between spatial and environmental effects on species composition. For a thorough discussion on partial Mantel tests see Legendre (2000). Interpretation of Mantel test results follows the causal model predictions of Legendre (1993). In this paper Legendre suggests four major models explaining causal relationships between ECMs, GDMs and SDMs. Mantel tests are based on simple cross-products term and are normalized so that it is equivalent to the familiar non-parametric Pearson product-moment correlation (Legendre \& Fortin 1989). The magnitude of Mantel correlations is often small even when highly significant statistically (Mantel-Pearson paradox, Dutilleul et al. 2000). Simple Mantel-tests were used to test for spatial autocorrelation of sampling units using ECM and GDM
(Anselin 1995). No significant correlation indicates independence of sampling units. All statistical tests were performed using the free software $\mathrm{R}$ ( $\mathrm{R}$ : A language and environment for statistical computing, $\mathrm{R}$ Foundation for Statistical Computing, Vienna, Austria).

\section{RESULTS}

\section{Community composition}

We recorded a total of 3431 individuals of 14 species belonging to two families during $382.5 \mathrm{~h}$ of visual and acoustic transect sampling in TNP, and 4227 individuals of 14 species belonging to three families during $393.5 \mathrm{~h}$ of visual and acoustic transect sampling in MHFR, respectively.

Community composition was tremendously affected by disturbance in communities of both realms. Species richness and thus composition differed significantly between communities of primary and exploited forest sites in both realms. Figure 1 depicts typical representatives
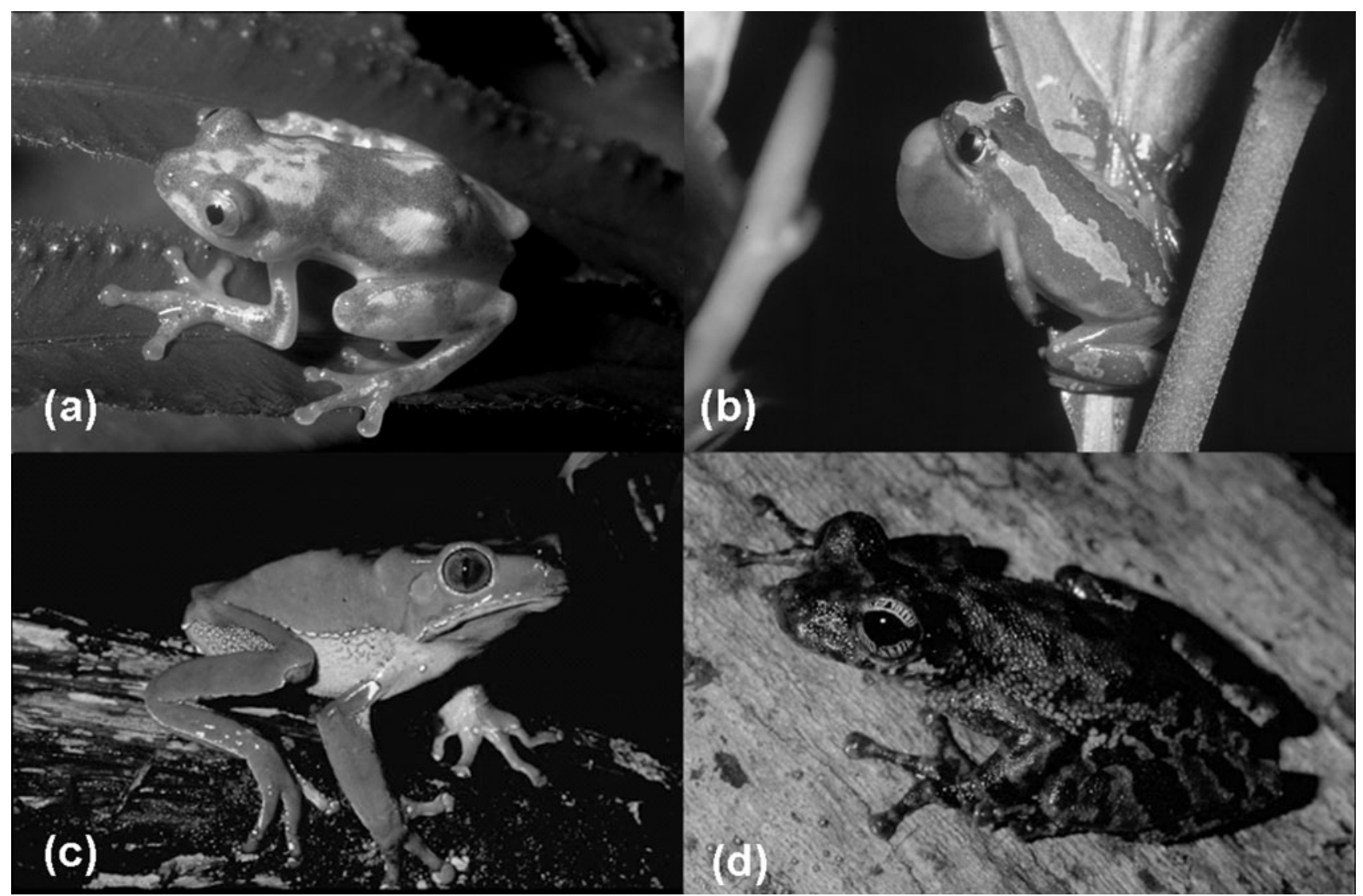

Figure 1. Typical representatives of the aboreal frog assemblages of Taï National Park (a and b) and Mabura Hill Forest Reserve (c and d). (a) and (c) are restricted to primary forest; (b) occurs only in exploited forest and (d) occurs in both primary and exploited forest. Compare Table 1. Afrixalus vibekensis (a); Afrixalus dorsalis (b); Phyllomedusa bicolor (c); Osteocephalus oophagus (d). 
Table 1. Species composition of arboreal frog communities in Taï National Park (TNP) and Mabura Hill Forest Reserve (MHFR). Complete $=$ recorded in primary or exploited forest transects; primary = recorded in primary forest transects; exploited = recorded in exploited forest transects. $+=$ recorded, $-=$ not recorded. Entries in parentheses refer to respective seasons; first entry before semicolon $=$ wet season, second entry after semicolon = dry season. Nomenclature follows Amphibian species of the world: an online reference. Version 5.0 (1 February 2007). http://research.amnh.org/herpetology/amphibia/index.php

\begin{tabular}{|c|c|c|c|c|c|c|c|}
\hline \multirow[b]{2}{*}{ Species } & \multicolumn{3}{|c|}{ TNP } & \multirow[b]{2}{*}{ Species } & \multicolumn{3}{|c|}{ MHFR } \\
\hline & Complete & Primary & Exploited & & Complete & Primary & Exploited \\
\hline Acanthixalus sonjae & $+(+,-)$ & - & $+(+,-)$ & Dendropsophus brevifrons & $+(+,-)$ & $+(+,-)$ & - \\
\hline Afrixalus dorsalis & $+(+,+)$ & - & $+(+,+)$ & Dendropsophus minusculus & $+(+,-)$ & $+(+,-)$ & - \\
\hline Afrixalus nigeriensis & $+(+,+)$ & $+(+,+)$ & $+(+,-)$ & Hypsiboas boans & $+(+,+)$ & $+(+,+)$ & - \\
\hline Afrixalus vibekensis & $+(+,-)$ & $+(+,-)$ & - & Hypsiboas calcaratus & $+(+,+)$ & $+(+,+)$ & - \\
\hline Hyperolius chlorosteus & $+(+,+)$ & $+(+,+)$ & $+(+,-)$ & Hypsiboas geographicus & $+(+,+)$ & $+(+,+)$ & - \\
\hline Hyperolius concolor & $+(-,+)$ & $+(-,+)$ & - & Hypsiboas granosus & $+(+,+)$ & $+(+,+)$ & $+(+,-)$ \\
\hline Hyperolius fusciventris & $+(+,-)$ & $+(+,-)$ & - & Osteocephalus leprieurii & $+(+,+)$ & $+(+,+)$ & - \\
\hline Hyperolius nienokouensis & $+(+,-)$ & $+(+,-)$ & - & Osteocephalus oophagus & $+(+,+)$ & $+(+,+)$ & $+(+,+)$ \\
\hline Hyperolius sylvaticus & $+(+,+)$ & $+(+,+)$ & $+(+,-)$ & Osteocephalus taurinus & $+(+,+)$ & $+(+,+)$ & $+(+,+)$ \\
\hline Hyperolius zonatus & $+(+,+)$ & $+(+,-)$ & $+(+,+)$ & Phyllomedusa bicolor & $+(+,+)$ & $+(+,+)$ & - \\
\hline Leptopelis spiritusnoctis & $+(+,+)$ & $+(+,+)$ & $+(+,+)$ & Phyllomedusa vaillantii & $+(+,+)$ & $+(+,+)$ & - \\
\hline Leptopelis macrotis & $+(+,+)$ & $+(+,+)$ & $+(+,-)$ & Trachycephalus resinifictrix & $+(+,+)$ & $+(+,+)$ & $+(+,+)$ \\
\hline Leptopelis occidentalis & $+(+,+)$ & $+(+,+)$ & $+(+,+)$ & Hyalinobatrachium sp. 1 & $+(+,+)$ & $+(+,+)$ & - \\
\hline Chiromantis rufescens & $+(+,+)$ & $+(+,+)$ & $+(+,-)$ & Eleutherodactylus marmoratus & $+(+,+)$ & $+(+,+)$ & $+(+,+)$ \\
\hline Total & $14(13,10)$ & $12(11,8)$ & $10(10,4)$ & Total & $14(14,12)$ & $14(14,12)$ & $5(5,4)$ \\
\hline
\end{tabular}

of the arboreal frog communities of TNP and MHFR associated with primary and exploited forest, respectively. Yet, changes differed qualitatively between the African and the South American sites. Whereas exploited forest communities of MHFR comprised an impoverished subset of primary forest communities with no species turnover (all species recorded in exploited forest sites occurred in primary forest), species reduction in exploited forest communities of TNP was less pronounced, however species turnover occurred (two species not recorded in primary forest, Table 1). The number of species recorded was subject to seasonal changes. Of the 14 species recorded in the entire MHFR community, only 12 species could be recorded during the dry season. All 14 were recorded during the wet season and in primary forest. Only five species have been proven to occur in exploited sites, only four of them could be recorded during the dry season. Primary forest records in the dry season included all 12 species recorded during that period (Table 1).

The situation in TNP was similar with respect to seasonal differences in the number of species recorded in each of the habitat types. The actual pattern, however, deviated from the pattern found in MHFR. In TNP only 10 out of the 14 species recorded in the entire TNP community were recorded during the dry season, and only 13 during the wet season. A total of 12 species was detected in primary forest and only 10 occurred in exploited forest. Eleven out of 12 primary forest species were detected during the wet season, eight species were detected during the dry season, one of which (Hyperolius concolor) was recorded during the dry season exclusively. In exploited forest, differences between rainy and dry season records were even more pronounced. During the wet season, all ten exploited forest species were recorded. Species number was reduced to only four species in the dry season. None of these species was recorded during the dry season exclusively (Table 1).

\section{Community predictability}

Observed predictability patterns were consistent within and between respective geographic realms (Africa versus South America) and disturbance regimes (primary versus exploited). Overall similarity between communities was low, but showed significant positive spatial correlation. In all cases tested, species distribution vector matrices (SDM) and geographic distance vector matrices (GDM) were significantly correlated when controlling for environmental effects in partial Mantel analyses, indicating that SUs in close proximity have similar species assemblages (spatial signal, Tables 2 and 3 ).

No significant correlations were found between SDM and ECM (environmental distribution vector matrix) when controlling for spatial effects, respectively (no environmental response signal, Tables 2 and 3). Hence, general correlative patterns were entirely determined by spatial dynamics.

These results were consistent throughout both seasons (no temporal signal) and disturbance regimes (no disturbance signal). In both geographic realms, results therefore indicated a general increase in community predictability with increasing proximity of SUs in both forest types. There was a single exception to this general 
Table 2. Partial Mantel test on comparison of three different distance matrices Mabura Hill Forest Reserve (MHFR). Entire study period, primary versus exploited forest habitats; dry and wet season, primary versus secondary forest habitats; randomization (Monte Carlo) test (10,000 permutations); $\mathrm{r}=$ standardized Mantel statistic. Statistically significant results are marked with ${ }^{*} \mathrm{P} \leq 0.01$ and ${ }^{* *} \mathrm{P} \leq 0.001$. In bold, matrices that were partialled out in respective analysis. Simple Mantel test comparisons on geographic and environmental matrices included in the table represent tests for spatial autocorrelation.

\begin{tabular}{|c|c|c|c|c|c|c|}
\hline \multirow[b]{2}{*}{ Matrices compared } & \multicolumn{3}{|c|}{ Primary } & \multicolumn{3}{|c|}{ Exploited } \\
\hline & $\mathrm{r}$ & $\mathrm{P}$ & $\begin{array}{l}\text { Empirical } 95 \% / 99 \% \\
\text { confidence limits of } r\end{array}$ & $\mathrm{r}$ & $\mathrm{P}$ & $\begin{array}{l}\text { Empirical 95\%/99\% } \\
\text { confidence limits of } \mathrm{r}\end{array}$ \\
\hline \multicolumn{7}{|l|}{ Entire study period } \\
\hline Species-environmental-geographic (entire) & 0.095 & 0.979 & $0.091 / 0.131$ & 0.091 & 0.035 & $0.081 / 0.120$ \\
\hline Species-geographic-environmental (entire) & 0.102 & $<0.001^{* *}$ & $0.032 / 0.047$ & 0.174 & $<0.001^{* *}$ & $0.080 / 0.118$ \\
\hline Geographic-environmental (entire) & 0.054 & 0.139 & $0.042 / 0.053$ & 0.054 & 0.139 & $0.058 / 0.076$ \\
\hline \multicolumn{7}{|l|}{ Separated according to season } \\
\hline Species-environmental-geographic (dry) & 0.042 & 0.771 & $0.094 / 0.136$ & 0.013 & 0.351 & $0.067 / 0.099$ \\
\hline Species-geographic-environmental (dry) & 0.152 & $<0.001^{* *}$ & $0.050 / 0.076$ & 0.031 & 0.188 & $0.063 / 0.092$ \\
\hline Geographic-environmental (dry) & 0.026 & 0.266 & $0.046 / 0.057$ & 0.026 & 0.266 & $0.054 / 0.074$ \\
\hline Species-environmental-geographic (wet) & 0.086 & 0.967 & $0.090 / 0.131$ & 0.087 & 0.043 & $0.082 / 0.119$ \\
\hline Species-geographic-environmental (wet) & 0.058 & $0.003^{*}$ & $0.031 / 0.048$ & 0.158 & $0.001^{* *}$ & $0.080 / 0.118$ \\
\hline Geographic-environmental (wet) & 0.051 & 0.154 & $0.041 / 0.061$ & 0.051 & 0.154 & $0.044 / 0.058$ \\
\hline
\end{tabular}

pattern. In the analysis of dry-season data in exploited forest communities of MHFR, SDM were not correlated with either GDM or ECM.

We also found no correlations between GDM and ECM in any of the 12 (MHFR and TNP, primary and exploited, wet season and dry season) pairwise matrix comparisons (simple Mantel tests). Thus sites in close proximity of each other did not have similar environmental characteristics. SUs can therefore be considered independent.

\section{DISCUSSION}

The predictability patterns of species composition in tree frog assemblages of two geographically distinct eco-regions were consistent both within respective realms and disturbance regimes, as well as between regions. All assemblages appeared to be spatially structured, i.e. sites in close proximity had similar species assemblages. However, spatially structured environmental variation did not account for the spatial structure of species incidence, as no correlations existed between environmental characteristic vector matrices (ECM) and geographic distance vector matrices (GDM). Thus sites in close proximity to each other did not share similar habitats and environmental similarity of sites can therefore not explain similar species composition. This corresponds to the space-only model of Legendre (1993, Figure 6). The pattern found in our study deviates in one important point from this model. In our analysis no environmental response signal was detected, i.e. sites with similar environmental characteristics did not support similar species assemblages. These results are in contrast to previously published results from studies on leaf litter

Table 3. Partial Mantel test on comparison of three different distance matrices Taï National Park (TNP). Entire study period, primary vs. exploited forest habitats; dry and wet season, primary vs. secondary forest habitats; randomization (Monte Carlo) test (10 000 permutations); $r=$ standardized Mantel statistic. Statistically significant results are marked with ${ }^{*} \mathrm{P} \leq 0.01$ and ${ }^{* *} \mathrm{P} \leq 0.001$. In bold, matrices that were partialled out in respective analysis. Simple Mantel test comparisons on geographic and environmental matrices included in the table represent tests for spatial autocorrelation.

\begin{tabular}{|c|c|c|c|c|c|c|}
\hline \multirow[b]{2}{*}{ Matrices compared } & \multicolumn{3}{|c|}{ Primary } & \multicolumn{3}{|c|}{ Exploited } \\
\hline & $\mathrm{r}$ & $\mathrm{P}$ & $\begin{array}{l}\text { Empirical } 95 \% / 99 \% \\
\text { confidence limits of } \mathrm{r}\end{array}$ & $\mathrm{r}$ & $\mathrm{P}$ & $\begin{array}{l}\text { Empirical } 95 \% / 99 \% \\
\text { confidence limits of } \mathrm{r}\end{array}$ \\
\hline \multicolumn{7}{|l|}{ Entire study period } \\
\hline Species-environmental-geographic (entire) & 0.096 & 0.016 & $0.069 / 0.099$ & 0.012 & 0.396 & $0.194 / 0.259$ \\
\hline Species-geographic-environmental (entire) & 0.136 & $<0.001^{* *}$ & $0.053 / 0.083$ & 0.212 & $0.014^{*}$ & $0.149 / 0.233$ \\
\hline Geographic-environmental (entire) & 0.054 & 0.139 & $0.044 / 0.056$ & 0.042 & 0.300 & $0.047 / 0.062$ \\
\hline \multicolumn{7}{|l|}{ Separated according to season } \\
\hline Species-environmental-geographic (dry) & 0.0875 & 0.019 & $0.069 / 0.099$ & 0.045 & 0.595 & $0.225 / 0.313$ \\
\hline Species-geographic-environmental (dry) & 0.160 & $<0.001^{* *}$ & $0.048 / 0.073$ & 0.303 & $0.004^{*}$ & $0.179 / 0.261$ \\
\hline Geographic-environmental (dry) & 0.026 & 0.266 & $0.049 / 0.061$ & 0.071 & 0.270 & $0.054 / 0.069$ \\
\hline Species-environmental-geographic (wet) & 0.067 & 0.056 & $0.070 / 0.102$ & 0.0350 & 0.308 & $0.226 / 0.315$ \\
\hline Species-geographic-environmental (wet) & 0.132 & $<0.001^{* *}$ & $0.053 / 0.078$ & 0.132 & $<0.001^{* *}$ & $0.051 / 0.079$ \\
\hline Geographic-environmental (wet) & 0.051 & 0.154 & $0.044 / 0.055$ & 0.053 & 0.293 & $0.055 / 0.072$ \\
\hline
\end{tabular}


anurans in West Africa (Ernst \& Rödel 2005) and anuran assemblages of forest streams in eastern Australia (Parris 2004) and thus need further explanation.

\section{Species composition and turnover}

Species composition varied considerably between habitat complexes in both realms. We noted a decrease in the total number of species, moving from primary forest to exploited forest. This was particularly marked in tree frog assemblages of MHFR where nine species were lost in disturbed forests. The species reduction in MHFR particularly concerned closed forest species, especially those associated with lotic habitats or those exhibiting reproductive strategies in which clutches are attached to vegetation above aquatic habitats and a large proportion of larval development takes place outside standing bodies of water (e.g. in MHFR: Hyalinobatrachium sp., Phyllomedusa spp., Dendropsophus spp.). Similar patterns have previously been reported for Amazonian frog communities (Tocher et al. 2001). The species reduction in TNP was less severe (four species lost in exploited forest) and concerned mainly small-bodied hyperoliid frogs that attach clutches to vegetation above lentic aquatic habitats (Afrixalus vibekensis, Hyperolius nienokouensis, Hyperolius fusciventris). In the case of TNP, no one habitat complex was found to have the full complement of species present in the TNP landscape. In MHFR on the other hand primary forest communities contained all species found in the MHFR landscape. Exploited forest communities were hence an impoverished subset of the entire MHFR community. However, even in MHFR we recorded three species (Dendropsophus minutus, Hypsiboas crepitans and Scinax ruber, each with a single individual) associated with disturbed sites that were not recorded in primary forest communities. These species were not recorded during transect walks and hence not included in the analysis, as they cannot (yet?) be considered part of the exploited-forest community. They rather appeared to be invading the area from an outside source; most likely accessing the reserve area via the main access road (Ernst et al. 2005). Species turnover in exploited-forest communities of TNP also involves mainly species that are known to be comparatively efficient dispersers and invaders. In West Africa these species are commonly referred to as farmbush elements (sensu Schiøtz 1967), Afrixalus dorsalis being one prominent example. In the case of TNP, previous invasions of this species have apparently been successful, as it appears to maintain stable populations in exploited forest and was hence frequently and regularly recorded during transect walks. Two species exclusively recorded in primary forest are generally considered farmbush (Hyperolius concolor) or disturbance (Hyperolius fusciventris) elements
(Rödel 2000, Rödel \& Ernst 2003, Rödel et al. 2005) and their absence in exploited forest needs further explanation. Whereas Hyperolius fusciventris is a true forest species that can cope considerably well with altered environmental conditions following human-induced disturbance, Hyperolius concolor has been reported to occur in the transitory zone between rain forest and savanna and even penetrates far into true savanna habitats (Rödel 2000). The record of this species in a single primary forest site may be comparable with the situation of the three invading hylid species in MHFR and represent a random invasion event (an old logging road connects to this particular primary forest site). We observed amplectant pairs of Hyperolius concolor but successful reproduction was not confirmed.

\section{Community predictability}

The composition of the arboreal frog communities in both geographic realms proved to be determined by spatial factors, exclusively. The only deviation (no correlations between SDM and either GDM or ECM in dry-season data in exploited-forest communities of MHFR) is most likely a sampling artifact, due to a comparatively small sample size in exploited sites during the dry season. Results thus support biotic control model aspects, regardless of the disturbance status of a given forest and the geographic realm. In all cases, sites that were geographically proximal tended to have similar communities. This is an indication that biotic processes, such as dispersal from particular species pools, may influence the composition of communities at the cross regional level. This in turn is based on the assumption that priority effects (Wilbur \& Alford 1985) and lottery recruitment mechanisms (Chesson \& Warner 1981, Munday et al. 2000) are more important in the assembly of communities than speciesspecific responses to an environmental gradient.

Nonetheless, a large proportion of species that makes up the arboreal frog communities of MHFR $(>70 \%)$ and TNP $(>75 \%)$ has very specific breeding habitat requirements, i.e. species depend on specific lotic or large lentic aquatic habitats for reproduction (Ernst et al. 2006). Provided that individuals can move freely across the entire habitat matrix and that preferred breeding habitats are regularly available, this may not represent a limiting factor in the assembly of a given community. Dispersal and colonization abilities of a particular species, rather than species-specific habitat association thus become more important in determining community composition. This scenario reflects the situation in primary forest very well. However, the availability of specific breeding habitats in exploited forest sites is usually either reduced or their occurrence becomes highly unpredictable as formerly aquatic sites change from more permanent to increasingly 
ephemeral character. As a result the community in these exploited sites is reduced to members that exhibit a rather broad-scale habitat tolerance or show high levels of response diversity (sensu Elmqvist et al. 2003). Others possess special adaptations that enable them to cope with the harsher conditions in these disturbed forest patches, e.g. direct developers or species that breed in phytotelmata with a well-developed water-holding capacity. Species that depend on large, and/or permanent, aquatic sites for reproduction simply go extinct as is reflected in species composition and turnover patterns.

The same mechanisms operating in primary forest communities would then apply to the remaining community in exploited forests. The combination of species-specific dispersal abilities and the occurrence of dispersal barriers, such as large canopy gaps or forest clearings may ultimately determine species composition rather than environmental factors associated with respective sites. This finally explains why species habitat correlations within a respective habitat type may rather be overlain by spatial dynamics as has been observed in this study (strong spatial signal in all assemblages tested). In a recent study on birds, Bahn \& McGill (2007) found that abundance-environment correlations may simply result because both variables are similarly structured in space. Hence, the direct effect of environment on local abundance may be very small (not necessarily absent) and neighbourhood abundance may determine local abundance. This does not exclude environment from contributing to neighbourhood abundance. However, population processes, such as dispersal, immigration and emigration modify abundance locally as has previously been suggested by Currie (2007) in a paper on the roles of environment and space in ecology. This pattern is very similar to the pattern revealed in our study and may possibly prove to be a common pattern in vertebrate communities.

Additional evidence for this pattern comes from a study on patterns of nestedness and species associations in pond-dwelling amphibians. In this study Hecnar \& M'Closkey (1997) showed that species grouped as good dispersers were less nested than poor dispersers and species incidence was positively correlated with potential dispersal ability. It is obvious that this is likely to determine the species composition of a given assemblage considerably, especially if priority effects (Wilbur \& Alford 1985) are an important factor shaping newly assembled communities.

In our case the assemblages in each of the habitat types may be dominated by species that can successfully colonize a given patch, which leads to a dominance of the spatial signal, perhaps even to a point at which an environmental response of a particular species is entirely covered or overlain by the spatial response signal. However, this remains speculative as actual species-specific dispersal and colonization rates need to be investigated systematically. It would have far-reaching consequences for the dynamics and conservation of arboreal frog assemblages if interactions between speciesspecific dispersal abilities and the occurrence of dispersal barriers, created by human activities such as commercial logging, actually determine the composition of a given assemblage rather than species-specific responses to the environment. Regardless of the actual mechanism, the spatial pattern that was revealed here deserves further attention. Even more so since patterns appear to differ between different anuran groups (arboreal frogs versus, for example, leaf-litter frogs).

When comparing the results of Ernst \& Rödel (2005) and Parris (2004) with those of the study presented here, it seems likely that the patterns derived from the analysis of entire amphibian assemblages actually reflect the idiosyncratic influence of different functional response groups on general compositional patterns of the entire community. Treating distinct anuran groups as one coherent entity in the analysis of patterns of species composition may actually obscure or confound patterns that are otherwise group specific. This is in concordance with results from our study on the effects of anthropogenic disturbance on functional diversity of anuran communities (Ernst et al. 2006) that showed that different functional response groups react differently to habitat alteration. We therefore advocate studies that incorporate these group-specific differences, especially because important conservation strategies for this highly threatened vertebrate group may otherwise be based on the wrong assumptions.

\section{ACKNOWLEDGEMENTS}

RE was supported by a doctoral scholarship from the German Academic Exchange Service (DAAD). Iwokrama International Centre for Rain Forest Conservation and Development helped with transportation and various administrative services. Working in MHFR was kindly permitted by head of the Guyana Forestry CommissionPRDD, R. Thomas. Permission to conduct biodiversity research in Guyana was given by the Environmental Protection Agency Guyana. The field study in Africa was part of the BIOLOG-program of the German Ministry of Education and Science (BMB+F; Project W08 BIOTAWest, FZ 01 LC 00410). Research and access permissions were given by the Ministère de l'Enseignement Supérieur et de la Recherche Scientifique, and the Ministère de la Construction et de l'Environnement of the Republic of Ivory Coast. Three anonymous reviewers improved the manuscript by constructive comments. These supports are gratefully acknowledged. 


\section{LITERATURE CITED}

ANSELIN, L. 1995. Local indicators of spatial association - LISA. Geographical Analysis 27:93-115.

AZAVEDO-RAMOS, C., MAGNUSSON, W. E. \& BAYLISS, P. 1999. Predation as the key factor structuring tadpole assemblages in a savanna area in central Amazonia. Copeia 1999:22-33.

BAHN, V. \& MCGILL, B. J. 2007. Can niche-based distribution models outperform spatial interpolation? Global Ecology and Biogeography 16:733-742.

BEADLE, N. C. W. 1966. Soil phosphate and its role in molding segments of Australian flora and vegetation with special reference to xeromorphy and sclerophylly. Ecology 47:992-1007.

BEEBEE, T. J. C. \& GRIFFITHS, R. A. 2005. The amphibian decline crisis. A watershed for conservation biology? Biological Conservation 25:271-285.

BOCARD, D., LEGENDRE, P. \& DRAPEAU, P. 1992. Partialling out the spatial component of ecological variation. Ecology 73:10451055.

BOWNE, D. R. \& BOWERS, M. A. 2004. Interpatch movements in spatially structured populations: a literature review. Landscape Ecology 19:1-20.

CARR, L. W. \& FAHRIG, L. 2001. Effect of road traffic on two amphibian species of different vagility. Conservation Biology 15:1071-1078.

CHESSON, P. L. \& WARNER, R. R. 1981. Environmental variability promotes coexistence in lottery competitive systems. American Naturalist 117;923-943.

CLEMENTS, F. E. 1916. Plant succession. Carnegie Institute of Washington Publications 242.

CONNELL, J. H. 1983. On the prevelance and relative importance of interspecific competition: evidence from experiments. American Naturalist 122:661-697.

CURRIE, D. J. 2007. Disentangling the roles of environment and space in ecology. Journal of Biogeography 34:2009-2011.

CUSHMAN, S. A. \& MCGARIGAL, K. 2004. Hierarchical analysis of forest bird species-environment relationships in the Oregon Coast Range. Ecological Applications 14:1090-1105.

DUELLMAN, W. E. 1988. Patterns of species diversity in anuran amphibians in the American tropics. Annals of the Missouri Botanical Garden 75:79-104.

DUELLMAN, W. E. 1999. Patterns of distribution of amphibians: a global perspective. The John Hopkins University Press, Baltimore. 648 pp.

DUTILLEUL, P., SOCKWELL, D., FRIGON, D. \& LEGENDRE, P. 2000. The Mantel-Pearson paradox: statistical considerations and ecological implications. Journal of Agricultural, Biological, and Environmental Statistics 5:131-150.

ELMQVIST, T., FOLKE, C., NYSTRÖM, M., PETERSON, G., BENGTSSON, J., WALKER, B. \& NORBER, J. 2003. Response diversity, ecosystem change, and resilience. Frontiers in Ecology and the Environment $1: 488-496$.

ERNST, R. \& RÖDEL, M.-O. 2005. Anthropogenically induced changes of predictability in tropical anuran assemblages. Ecology 86:31113118.

ERNST, R. \& RÖDEL, M.-O. 2006. Community assembly and structure of tropical leaf litter anurans. Ecotropica 12:113-130.
ERNST, R., RÖDEL, M.-O. \& ARJOON, D. 2005. On the cutting edge the anuran fauna of the Mabura Hill Forest Reserve, Central Guyana. Salamandra 41:179-194.

ERNST, R., LINSENMAIR, K. E. \& RÖDEL, M.-O. 2006. Diversity erosion beyond the species level: Dramatic loss of functional diversity after selective logging in two tropical amphibian communities. Biological Conservation 133:143-155.

ERNST, R., LINSENMAIR, K. E., THOMAS, R. \& RÖDEL, M.-O. 2007. Amphibian communities in disturbed forests - lessons from the Neo-, and Afrotropics. Pp. 61-87 in Tscharntke, T., Leuschner, C., Guhardja, E. \& Bidin, A. (eds). The stability of tropical rainforest margins, linking ecological, economic and social constraints of land use and conservation. Springer Verlag, Berlin.

FAITH, D., MINCHIN, P. R. \& BELBIN, L. 1987. Compositional dissimilarity as a robust measure of ecological distance. Vegetatio 69:57-68.

GARDNER, T. A. \& FITZHERBERT, E. B. 2007. Spatial and temporal patterns of abundance and diversity of an East African leaf litter amphibian fauna. Biotropica 39:105-113.

GARDNER, T. A., RIBEIRO-JÚNIOR, M. A., BARLOW, J., SAUER ÁVILAPIRES, T. C., HOOGMOED, M. S. \& PERES, C. A. 2007. The value of primary, secondary, and plantation forests for a neotropical herpetofauna. Conservation Biology 21:775-787.

GASTON, K. J. \& BLACKBURN, T. M. 2000. Pattern and process in macroecology. Blackwell Science, Oxford. 377 pp.

GLEASON, H. A. 1917. The structure and development of the plant association. Bulletin of the Torrey Botanical Club 44:463-481.

GLEASON, H. A. 1926. The individualistic concept of the plant association. Bulletin of the Torrey Botanical Club 53:7-26.

HECNAR, S. J. \& M'ClOSKEY, R. T. 1997. Patterns of nestedness and species association in a pond-dwelling amphibian fauna. Oikos 80:371-381.

HERO, J. M., GASCON, C. \& MAGNUSSON, W. E. 1998. Direct and indirect effects of predation on tadpole community structure in the Amazon rain forest. Australian Journal of Ecology 23:474482.

HOULAHAN, J. E. \& FINDLAY, C. S. 2003. The effects of adjacent land use on wetland amphibian species richness and community composition. Canadian Journal of Fishery and Aquatic Sciences 60:1078-1094.

JEFFRIES, M. J. 2003. Idiosyncratic relationships between pond invertebrates and environmental, temporal and patch-specific predictors of incidence. Ecography 26:311-324.

LEGENDRE, P. 1993. Spatial autocorrelation: trouble or new paradigm? Ecology 74:1659-1673.

LEGENDRE, P. 2000. Comparison of permutation methods for the partial correlation and partial Mantel tests. Journal of Statistical Computation and Simulation 67:37-73.

LEGENDRE, P. \& FORTIN, M. J. 1989. Spatial pattern and ecological analysis. Vegetatio 80:107-138.

LEGENDRE, P. \& LEGENDRE, L. 1998. Numerical ecology. Developments in environmental modeling, 20. Elsevier Science, Amsterdam. $970 \mathrm{pp}$.

LEIBOLD, M. A., HOLT, R. D. \& HOLYOAK, M. 2005. Adaptive and coadaptive dynamics in metacommunities - tracking environmental change at different spatial scales. Pp. 439-464 in Holyoak, M., 
Leibold, M. A. \& Holt, R. D. (eds.). Metacommunities - spatial dynamics and ecological communities. The University of Chicago Press, Chicago.

LEPŠ, J. \& ŠMILAUER, P. 2004. Multivariate analysis of ecological data. Faculty of Biological Sciences, University of South Bohemia, České Budějovice. 242 pp.

MAGURRAN, A. E. 2004. Measuring biological diversity. Blackwell Publishing, Oxford. 256 pp.

MCCARTHY, M. A. 1997. Competition and dispersal from multiple nests. Ecology 78:873-883.

MCCARTHY, M. A. \& LINDENMAYER, D. B. 2000. Spatially-correlated extinction in a metapopulation model of Leadbeater's possum. Biodiversity and Conservation 9:47-63.

MCINTOSH, R. P. 1995. H. A. Gleason's 'individualistic concept' and theory of animal communities: a continuing controversy. Biological Reviews 70:317-357.

MUNDAY, P. L., JONES, G. P. \& CALEY, M. J. 2000. Interspecific competition and coexistence in a guild of coral-dwelling fishes. Ecology 82:2177-2189.

NEAVE, H. M., CUNNINGHAM, R. B., NORTON, T. W.\& NIX, H. A. 1996. Biological inventory for conservation evaluation 3. Relationships between birds, vegetation and environmental attributes in southern Australia. Forest Ecology and Management 85:197-218.

PARRIS, K. M. 2004. Environmental and spatial variables influence the composition of frog assemblages in sub-tropical eastern Australia. Ecography 27:392-400.

PLUMPTRE, A. J. 1996. Changes following 60 years of selective timber harvesting in the Budongo Forest Reserve, Uganda. Forest Ecology and Management 89:101-113.

RIEZEBOS, E. P., VOOREN, A. P. \& GUILlAUMET, J. L. 1994. Le Parc National de Taï, Côte d'Ivoire. Tropenbos Series 8, Wageningen, The Netherlands. $322 \mathrm{pp}$.

RÖDEL, M.-O. 2000. Herpetofauna of West Africa, Vol. I: Amphibians of the West African savanna. Edition Chimaira, Frankfurt. 332 pp.

RÖDEL, M.-O. \& ERNST, R. 2003. The amphibians of Marahoué and Mont Péko National Parks, Ivory Coast. Herpetozoa 16:2339.

RÖDEL, M.-O.\&ERNST, R. 2004. Measuring and monitoring amphibian diversity in tropical forests. I. An evaluation of methods with recommendations for standardization. Ecotropica 10:1-14.
RÖDEL, M.-O., GIL, M., AGYEI, A. C., LEACHÉ, A. D., DIAZ, R. E., FUJITA, M. K. \& ERNST, R. 2005. The amphibians of the forested parts of south-western Ghana. Salamandra 41:107-127.

SCHIØTZ, A. 1967. The treefrogs (Rhacophoridae) of West Africa. Spolio Zoologica Musei Hauniensis 25:1-346.

SKELLY, D. K. 1995. A behavioural trade-off and its consequences for the distribution of Pseudacris treefrog larvae. Ecology 76:150-164.

SMOUSE, P.E., LONG, J. C.\& SOKAL, R. R. 1986. Multiple regression and correlation extensions of the Mantel test of matrix correspondence. Systematic Zoology 35:627-632.

STUART, S. N., CHANSON, J. S., COX, N. A., YOUNG, B. E., RODRIGUES, A. S. L., FISCHMAN, D. L. \& WALLER, R. W. 2004. Status and trends of amphibian declines and extinctions worldwide. Science 306:17831786.

TER STEEGE, H., BOOT, R. G. A., BROUWER, L. C., CAESAR, J. C., EK, R. C., HAMMOND, D. S., HARIPERSAUD, P. P., VAN DER HOUT, P., JETTEN, V. G., VAN KEKEM, A. J., KELLMAN, M. A., KHAN, Z., POLAK, A. M., PONS, T. L., PULLES, J., RAAIMAKERS, D., ROSE, S. A., VAN DER SANDEN, J. J. \& ZAGT, R. J. 1996. Ecology and logging in a tropical rain forest in Guyana with recommendations for forest management. Tropenbos Series 14, Tropenbos Foundation, Wageningen. $123 \mathrm{pp}$.

TOCHER, M. D., GASCON, C. \& MEYER, J. 2001. Community composition and breeding success of Amazonian frogs in continuous forest and matrix-habitat aquatic sites. Pp. 235-247 in Bierregaard, R. O., Gascon, C., Lovejoy, T. E. \& Mesquita, R. (eds). Lessons from Amazonia: the ecology and conservation of a fragmented forest. Yale University Press, New Haven.

URBAN, D., GOSLEE, S., PIERCE, K. \& LOOKINGBILL, T. 2002. Extending community ecology to landscapes. Ecoscience 9:200-202.

VEITH, M., LÖTTERS, S., ANDREONE, F. \& RÖDEL, M.-O. 2004. Measuring and monitoring amphibian diversity in tropical forests. II. Estimating species richness from standardised transect census. Ecotropica 10;85-99.

WHITTAKER, R. H. 1956. Vegetation of the Great Smokey Mountains. Ecological Monographs 26:1-80.

WILBUR, H. M. \& ALFORD, R. A. 1985. Priority effects in experimental pond communities: responses of Hyla to Bufo and Rana. Ecology $66: 1106-1114$ 